BMJ Open

Diabetes

Research

\& Care

\title{
A Body shape index significantly predicts MRI-defined abdominal adipose tissue depots in non-obese Asian Indians with type 2 diabetes mellitus
}

\author{
Shajith Anoop, ${ }^{1,2,3,4}$ Jesse Krakauer, ${ }^{5}$ Nir Krakauer, ${ }^{6}$ Anoop Misra (D) ${ }^{1,2,3,4}$
}

To cite: Anoop S, Krakauer J, Krakauer $\mathrm{N}$, et al. A Body shape index significantly predicts MRI-defined abdominal adipose tissue depots in non-obese Asian Indians with type 2 diabetes mellitus. BMJ Open Diab Res Care 2020;8:e001324. doi:10.1136/ bmjdrc-2020-001324

\section{- Additional material is} published online only. To view please visit the journal online (http://dx.doi.org/10.1136/ bmjdrc-2020-001324).

Received 28 February 2020 Revised 10 July 2020 Accepted 13 July 2020
Check for updates

\section{(C) Author(s) (or their} employer(s)) 2020. Re-use permitted under CC BY-NC. No commercial re-use. See rights and permissions. Published by BMJ.

For numbered affiliations see end of article.

Correspondence to Dr Anoop Misra; anoopmisra@gmail.com

\section{ABSTRACT}

Introduction We aimed to determine the correlations of volumes of subcutaneous abdominal adipose tissue (SCAT) (anterior, posterior, superficial and deep), total SCAT, intraperitoneal adipose tissue, retroperitoneal abdominal adipose tissue (RPAT), total intra-abdominal adipose tissue (IAAT), pancreatic volume, liver span, total body fat (TBF) and truncal fat mass (TFM) with anthropometric indices, viz., A Body Shape Index (ABSI), Hip Index, their Z scores and Anthropometric Risk Index in non-obese (body mass index $(\mathrm{BMI})<25 \mathrm{~kg} / \mathrm{m}^{2}$ ) Asian Indians with type 2 diabetes mellitus (T2DM).

Research design and methods Non-obese patients with T2DM (cases; $n, 85$ ) and BMI-matched, healthy subjects (controls; $n, 38$ ) underwent anthropometry, dual energy $\mathrm{X}$ ray absorptiometry (DXA) for estimation of TBF, TFM and 1.5 T MRI for estimation of volumes of abdominal adipose tissue depots, pancreas and liver span. Spearman's correlation analysis and Receiver Operator Characteristic curve analysis were applied.

Results The Z score of ABSI (Z_ABSI) showed significantly positive correlation with volumes of all depots of abdominal SCAT, total IAAT and RPAT in cases. Area under the curve for $Z$ _ABSI (0.87) showed higher sensitivity: 82.0 $\%$, specificity: $81.5 \%$, at a predictive cut-off value of 0.49 for abdominal adiposity.

Conclusion In non-obese Asian Indians with T2DM, the Z_ABSI showed significant correlation with IAAT and SCAT and higher predictive accuracy for abdominal adiposity. Highlights of the study This is the first MRI-based study in the context of ABSI in non-obese $\left(B M I<25 \mathrm{~kg} / \mathrm{m}^{2}\right)$ Asian Indians with T2DM. Findings indicate that $Z$ _ABSI has high predictive accuracy for abdominal adiposity in non-obese Asian Indians. The Z_ABSI index showed significantly positive correlation with volumes of adipose tissue depots, viz., abdominal SCAT, total IAAT and RPAT in cases.

\section{INTRODUCTION}

The prevalence of type 2 diabetes mellitus (T2DM) is high in South Asians, ${ }^{1}$ and about $1 / 5$ th of Asian Indian patients with T2DM are non-obese (body mass index (BMI) $<25 \mathrm{~kg} /$ $\left.\mathrm{m}^{2}\right){ }^{2}$ While Asian Indians have comparatively more subcutaneous abdominal adipose

\section{Significance of this study}

What is already known about this subject?

- Abdominal obesity is a major cause of insulin resistance and type 2 diabetes mellitus (T2DM) in nonobese (body mass index (BMI): $<25 \mathrm{~kg} / \mathrm{m}^{2}$ ) Asian Indians. We had previously shown the association of intra-abdominal adiposity and hepatic fat with T2DM in non-obese (BMl: $<25 \mathrm{~kg} / \mathrm{m}^{2}$ ) Asian Indians.

\section{What are the new findings?}

- In this study, the Z score of A Body Shape Index (Z $A B S I)$ showed significantly positive correlation with volumes of all depots of subcutaneous abdominal adipose tissue, total intra-abdominal adipose tissue and retroperitoneal adipose tissue in non-obese Asian Indians with T2DM. Area under the curve for Z_ABSI (0.87) showed higher sensitivity: $82.0 \%$, specificity: $81.5 \%$, at a predictive cut-off value of 0.49 for abdominal adiposity.

\section{How might these results change the focus of} research or clinical practice?

- The results of this study indicate high predictive value of the $Z_{-} A B S I$ for prediction of intra-abdominal obesity and T2DM in non-obese Asian Indians.

tissue (SCAT), intra-abdominal adipose tissue (IAAT) and hepatic fat associated with insulin resistance and higher cardiometabolic risk than whites, ${ }^{3}$ a reliable anthropometric parameter to correlate with abdominal adiposity needs further research.

Several anthropometric indices have been used to determine cardiovascular risk, most common being BMI and waist circumference (WC). These parameters have been used in the clinical assessment of cardiovascular risk in Asian Indians. ${ }^{4}$ Recently, A Body Shape Index (ABSI), Hip Index (HI), their Z scores and the Anthropometric Risk Index (ARI) have attracted research interest for their 
Table 1 Demographic, anthropometric and body composition profile of cases and controls

\begin{tabular}{|c|c|c|c|c|c|c|}
\hline \multirow[b]{2}{*}{ Variables } & \multicolumn{3}{|c|}{ Unadjusted for age } & \multicolumn{3}{|c|}{ Adjusted for age } \\
\hline & $\begin{array}{l}\text { Cases } \\
(n, 85)\end{array}$ & $\begin{array}{l}\text { Controls } \\
(n, 38)\end{array}$ & $P$ value & $\begin{array}{l}\text { Cases } \\
(n, 85)\end{array}$ & $\begin{array}{l}\text { Controls } \\
(n, 38)\end{array}$ & $P$ value \\
\hline Body mass index $\left(\mathrm{kg} / \mathrm{m}^{2}\right)$ & $22.2 \pm 2.0$ & $21.3 \pm 2.1$ & 0.21 & $22.6 \pm 1.6$ & $22.4 \pm 1.7$ & 0.33 \\
\hline Waist circumference (cm) & $83.7 \pm 6.8$ & $81.8 \pm 7.7$ & $<0.01$ & $84.1 \pm 4.8$ & $84.5 \pm 5.6$ & $<0.05$ \\
\hline Hip circumference (cm) & $89.5 \pm 4.6$ & $90.8 \pm 7.3$ & 0.23 & $87.3 \pm 4.8$ & $91.3 \pm 5.0$ & 0.06 \\
\hline WHR & $0.92 \pm 0.0$ & $0.89 \pm 0.0$ & $<0.001$ & $0.93 \pm 0.0$ & $0.0 .90 \pm 0.0$ & $<0.001$ \\
\hline WHt-R & $0.51 \pm 0.04$ & $0.49 \pm 0.04$ & 0.12 & $0.52 \pm 0.04$ & $0.48 \pm 0.04$ & 0.10 \\
\hline Mid-arm circumference (cm) & $27 \pm 2.3$ & $27.4 \pm 5.4$ & 0.52 & $27.2 \pm 2.8$ & $27.6 \pm 3.1$ & 0.53 \\
\hline Mid-thigh circumference (cm) & $48.5 \pm 3.9$ & $48.7 \pm 4.8$ & 0.24 & $49.7 \pm 3.8$ & $48.7 \pm 4.4$ & 0.26 \\
\hline Biceps skinfolds (mm) & $12.6 \pm 7.3$ & $8.2 \pm 4.1$ & $<0.01$ & $13.8 \pm 6.3$ & $8.3 \pm 5.7$ & $<0.01$ \\
\hline Triceps skinfolds (mm) & $13.4 \pm 5.2$ & $17.9 \pm 7.4$ & $<0.01$ & $15.5 \pm 0.3$ & $19.3 \pm 6.3$ & $<0.01$ \\
\hline Thigh skinfold (mm) & $26.2 \pm 8.9$ & $22.4 \pm 5.7$ & $<0.01$ & $26.2 \pm 7.5$ & $23.5 \pm 6.6$ & $<0.01$ \\
\hline Calf skinfold (mm) & $20.8 \pm 7.4$ & $10.9 \pm 4.9$ & $<0.01$ & $20.1 \pm 5.8$ & $12.4 \pm 5.7$ & $<0.01$ \\
\hline Subscapular skinfold (mm) & $20.8 \pm 5.6$ & $19.5 \pm 7.9$ & 0.80 & $21.9 \pm 6.7$ & $22.3 \pm 6.9$ & 0.8 \\
\hline Subscapular-triceps ratio & $1.4 \pm 0.04$ & $1.3 \pm 0.09$ & 0.30 & $1.4 \pm 0.03$ & $1.3 \pm 0.08$ & 0.29 \\
\hline Suprailiac skinfold (horizontal) & $19.7 \pm 5.1$ & $15.8 \pm 5.4$ & $<0.01$ & $19.7 \pm 4.6$ & $16.2 \pm 5.8$ & $<0.01$ \\
\hline Suprailiac skinfold (vertical) (mm) & $21.2 \pm 4.5$ & $17.2 \pm 3.9$ & $<0.05$ & $20.8 \pm 4.7$ & $18.0 \pm 8.4$ & $<0.05$ \\
\hline Suprailiac skinfold (average) (mm) & $19.2 \pm 5.3$ & $16.8 \pm 4.7$ & $<0.05$ & $18.9 \pm 5.0$ & $7.8 \pm 4.2$ & $<0.05$ \\
\hline Abdominal skinfold (vertical) (mm) & $24.1 \pm 6.5$ & $24.7 \pm 5.3$ & 0.87 & $24.6 \pm 8.1$ & $23.8 \pm 5.7$ & 0.61 \\
\hline Abdominal skinfold (horizontal) (mm) & $22.9 \pm 6.2$ & $23.7 \pm 5.4$ & 0.60 & $24.6 \pm 8.1$ & $24.8 \pm 5.7$ & 0.91 \\
\hline Abdominal skinfold (average) (mm) & $23.8 \pm 7.5$ & $24.1 \pm 5.3$ & 0.71 & $24.7 \pm 8.1$ & $24.0 \pm 5.7$ & 0.66 \\
\hline Abdominal skinfolds (total) (mm) & $48.7 \pm 10.6$ & $43.8 \pm 18.9$ & 0.07 & $48.7 \pm 13.8$ & $43.8 \pm 21.2$ & 0.05 \\
\hline \multicolumn{7}{|l|}{ Body composition (DXA) } \\
\hline Total fat mass $(\mathrm{kg})$ & $17.3 \pm 4.9$ & $18 \pm 5.4$ & 0.46 & $16.9 \pm 3.8$ & $17.5 \pm 4.7$ & 0.46 \\
\hline Truncal fat mass $(\mathrm{kg})$ & $8.5 \pm 2.9$ & $9.7 \pm 2.8$ & $<0.05$ & $8.5 \pm 2.2$ & $9.2 \pm 2.3$ & $<0.05$ \\
\hline Truncal fat (\%) & $32.5 \pm 6.8$ & $31.5 \pm 8.2$ & 0.52 & $32.5 \pm 6.3$ & $31.5 \pm 7.9$ & 0.48 \\
\hline Total fat (\%) & $27.7 \pm 6.2$ & $30.1 \pm 8.3$ & 0.08 & $27.8 \pm 5.4$ & $30.1 \pm 7.9$ & 0.06 \\
\hline
\end{tabular}

Values are presented as Mean $\pm S D, P<0.05$ : statistically significant.

Significant $P$ values are shown in bold.

DXA, dual energy X ray absorptiometry; WHR, waist-to-hip ratio; WHt-R, waist-to-height ratio.

potential as novel anthropometric indices to predict metabolic risk. The ABSI is calculated by dividing WC by the allometric regression of weight and height ${ }^{5}$ while the HI is derived by normalizing hip circumference for a given height and weight based on a power law. ${ }^{4}$ The ARI is derived by multiplying the calculated HRs of hip circumference, HI, BMI and ABSI. ${ }^{6}$ Some recent data suggest that these indices provide valid prediction of risk of diabetes, ${ }^{7}$ cardiovascular diseases ${ }^{8}$ and mortality risk in Koreans ${ }^{9}$ and Australians. ${ }^{10}$ However, the predictive accuracy of these indices for T2DM in Asian Indians remains unexplored. Since abdominal obesity (specifically abdominal and liver adiposity) increase metabolic and cardiovascular risk, ${ }^{11}$ any recently derived anthropometric indices must be validated against a standard measure. Specifically, it is not known if these indices could be correlated to volumes of IAAT, SCAT, liver span and pancreatic volume. Further, since many Asian Indians are non-obese and yet have T2DM, correlation studies would be of particular importance in this subgroup. In this case-control study on non-obese $\left(\mathrm{BMI}<25 \mathrm{~kg} / \mathrm{m}^{2}\right)$ Asian Indians with T2DM, we correlated the ABSI, HI, the $\mathrm{Z}$ scores of ABSI, HI and ARI with MRI-identified SCAT, IAAT and pancreatic volumes, liver span and dual energy $\mathrm{X}$ ray absorptiometry (DXA) quantified body composition measurements.

\section{METHODOLOGY}

This study was conducted in adherence to the ethical guidelines of the declaration of Helsinki 2013. ${ }^{12}$ Data for this study were obtained retrospectively from our previous report. ${ }^{13}$ The sample size for this MRI based study was calculated as minimum of 40 non-obese (BMI: $<25 \mathrm{~kg} / \mathrm{m}^{2}$ ) with T2DM as cases and a minimum of 20 BMI-matched, non-diabetic subjects as controls. The power of the study was $99.7 \%$ with an alpha error of $5 \%$ at $95 \%$ CI. 
Table 2 Correlation analysis for the ABSI and $\mathrm{HI}$ in cases and controls

\begin{tabular}{|c|c|c|c|c|c|c|c|c|}
\hline \multirow{3}{*}{$\begin{array}{l}\text { Anthropometric measures and variables } \\
\text { of body composition }\end{array}$} & \multicolumn{4}{|l|}{ ABSI } & \multicolumn{4}{|l|}{ HI } \\
\hline & \multicolumn{2}{|c|}{ Controls (n, 38) } & \multicolumn{2}{|c|}{ Cases $(n, 85)$} & \multicolumn{2}{|c|}{ Controls (n, 38) } & \multicolumn{2}{|c|}{ Cases $(n, 85)$} \\
\hline & rho & $P$ value & rho & $P$ value & rho & $P$ value & rho & $P$ value \\
\hline Age (years) & -0.14 & 0.40 & 0.38 & $<0.001$ & -0.13 & 0.41 & 0.21 & $<0.05$ \\
\hline BMI $\left(\mathrm{kg} / \mathrm{m}^{2}\right)$ & -0.31 & 0.05 & 0.02 & 0.81 & -0.37 & $<0.05$ & -0.21 & $<0.05$ \\
\hline WHR & -0.10 & 0.96 & 0.73 & $<0.001$ & -0.65 & 0.12 & -0.57 & $<0.01$ \\
\hline WHt-R & 0.78 & $<0.01$ & 0.62 & $<0.001$ & 0.54 & $<0.01$ & 0.10 & 0.95 \\
\hline Mid arm circumference & -0.11 & 0.51 & 0.21 & $<0.05$ & -0.12 & 0.48 & -0.10 & 0.32 \\
\hline Mid-thigh circumference & 0.18 & 0.28 & 0.06 & 0.58 & -0.00 & 0.96 & -0.22 & $<0.05$ \\
\hline \multicolumn{9}{|l|}{ Skinfolds (mm) } \\
\hline Biceps & 0.12 & 0.47 & -0.04 & 0.70 & 0.30 & 0.06 & 0.30 & $<0.01$ \\
\hline Triceps & 0.03 & 0.83 & 0.20 & 0.05 & 0.22 & 0.20 & 0.50 & $<0.01$ \\
\hline Thigh & 0.46 & $<0.05$ & 0.04 & 0.10 & 0.37 & $<0.05$ & 0.16 & 0.13 \\
\hline Calf & 0.17 & 0.31 & 0.20 & 0.05 & 0.20 & 0.23 & 0.31 & $<0.01$ \\
\hline Peripheral skinfolds (total) & 0.55 & 0.20 & 0.11 & 0.28 & 0.57 & $<0.01$ & 0.38 & $<0.01$ \\
\hline Subscapular & 0.28 & 0.09 & 0.30 & $<0.01$ & 0.22 & 0.19 & -0.07 & 0.50 \\
\hline Subscapular-triceps ratio & 0.19 & 0.26 & 0.13 & 0.22 & -0.06 & 0.73 & -0.60 & $<0.01$ \\
\hline Suprailiac (horizontal) & 0.07 & 0.66 & 0.13 & 0.08 & 0.16 & 0.34 & 0.08 & 0.44 \\
\hline Suprailiac (vertical) & 0.05 & 0.76 & 0.18 & 0.09 & 0.02 & 0.89 & 0.00 & 0.95 \\
\hline Suprailiac (average) & 0.12 & 0.49 & 0.19 & 0.07 & 0.11 & 0.50 & 0.04 & 676 \\
\hline Abdominal (vertical) & 0.12 & 0.20 & 0.17 & 0.10 & 0.15 & 0.41 & -0.02 & 0.80 \\
\hline Abdominal (horizontal) & 0.27 & 0.15 & 0.12 & 0.26 & 0.12 & 0.52 & -0.03 & 0.77 \\
\hline Abdominal skinfolds (total) & 0.40 & $<0.05$ & 0.14 & 0.18 & 0.42 & 0.01 & -0.01 & 0.92 \\
\hline Truncal skinfolds (total) & 0.33 & $<0.05$ & 0.23 & $<0.05$ & 0.31 & 0.06 & -0.04 & 0.96 \\
\hline Total body fat (\%) (on DXA) & -0.20 & 0.22 & 0.40 & $<0.05$ & -0.16 & 0.32 & 0.27 & $<0.05$ \\
\hline Truncal fat (\%) (on DXA) & -0.22 & 0.17 & 0.23 & $<0.05$ & -0.23 & 0.15 & 0.12 & 0.27 \\
\hline Truncal fat mass $(\mathrm{kg})$ (on DXA) & -0.17 & 0.30 & 0.25 & 0.02 & -0.24 & 0.14 & -0.05 & 0.64 \\
\hline \multicolumn{9}{|c|}{ Volumes of abdominal fat, pancreas and liver span on MRI (1.5 T) } \\
\hline Anterior SCAT $\left(\mathrm{cm}^{3}\right)$ & -0.30 & 0.07 & 0.30 & $<0.01$ & 0.29 & 0.07 & 0.12 & 0.25 \\
\hline Posterior SCAT $\left(\mathrm{cm}^{3}\right)$ & 0.07 & 0.66 & 0.24 & $<0.05$ & -0.10 & 0.52 & 0.02 & 0.85 \\
\hline Superficial SCAT $\left(\mathrm{cm}^{3}\right)$ & -0.23 & 0.16 & 0.23 & $<0.05$ & -0.25 & 0.13 & 0.06 & 0.56 \\
\hline Deep SCAT $\left(\mathrm{cm}^{3}\right)$ & -0.03 & 0.86 & 0.23 & $<0.01$ & -0.06 & 0.70 & 0.05 & 0.63 \\
\hline Total abdominal SCAT & -0.19 & 0.24 & 0.28 & $<0.01$ & -0.15 & 0.19 & 0.06 & 0.54 \\
\hline Retroperitoneal fat $\left(\mathrm{cm}^{3}\right)$ & -0.04 & 0.80 & 0.35 & $<0.01$ & -0.15 & 0.34 & -0.21 & $<0.05$ \\
\hline Intraperitoneal fat $\left(\mathrm{cm}^{3}\right)$ & -0.04 & 0.81 & 0.32 & $<0.01$ & -0.14 & 0.38 & -0.34 & $<0.01$ \\
\hline Total intra-abdominal fat $\left(\mathrm{cm}^{3}\right)$ & -0.04 & 0.80 & 0.37 & $<0.01$ & -0.15 & 0.36 & -0.33 & $<0.01$ \\
\hline Pancreatic volume $\left(\mathrm{cm}^{3}\right)$ & 0.16 & 0.34 & 0.19 & 0.07 & -0.23 & 0.16 & -0.06 & 0.54 \\
\hline Liver span (mm) & 0.18 & 0.28 & 0.06 & 0.54 & 0.10 & 0.54 & -0.14 & 0.19 \\
\hline
\end{tabular}

$P<0.05$ : statistically significant.

Significant $P$ values are shown in bold.

ABSI, A Body Shape Index; BMI, body mass index; DXA, dual energy X ray absorptiometry; HI, Hip Index; SCAT, subcutaneous abdominal adipose tissue; WHR, waist-to-hip ratio; WHt-R, waist-to-height ratio.

After obtaining informed consent, a cohort of nonobese $\left(\mathrm{BMI}<25 \mathrm{~kg} / \mathrm{m}^{2}\right)$ Asian Indians with T2DM (diagnosed within previous 1 year, cases $n, 85$ ) on metformin monotherapy and non-obese, healthy subjects (controls $\mathrm{n}, 38$ ) underwent comprehensive phenotyping (BMI and skinfold measurements at eight sites; namely, peripheral skinfolds (biceps, triceps, thigh and calf skinfolds), truncal skinfolds (subscapular, suprailiac and abdominal skinfolds (horizontal and vertical)) and subscapulartriceps ratio. In addition, circumference measurements of waist, hip, mid-arm and mid-thigh were done and waist-to-hip ratio (WHR), waist-to-height ratio (WHt-R) 


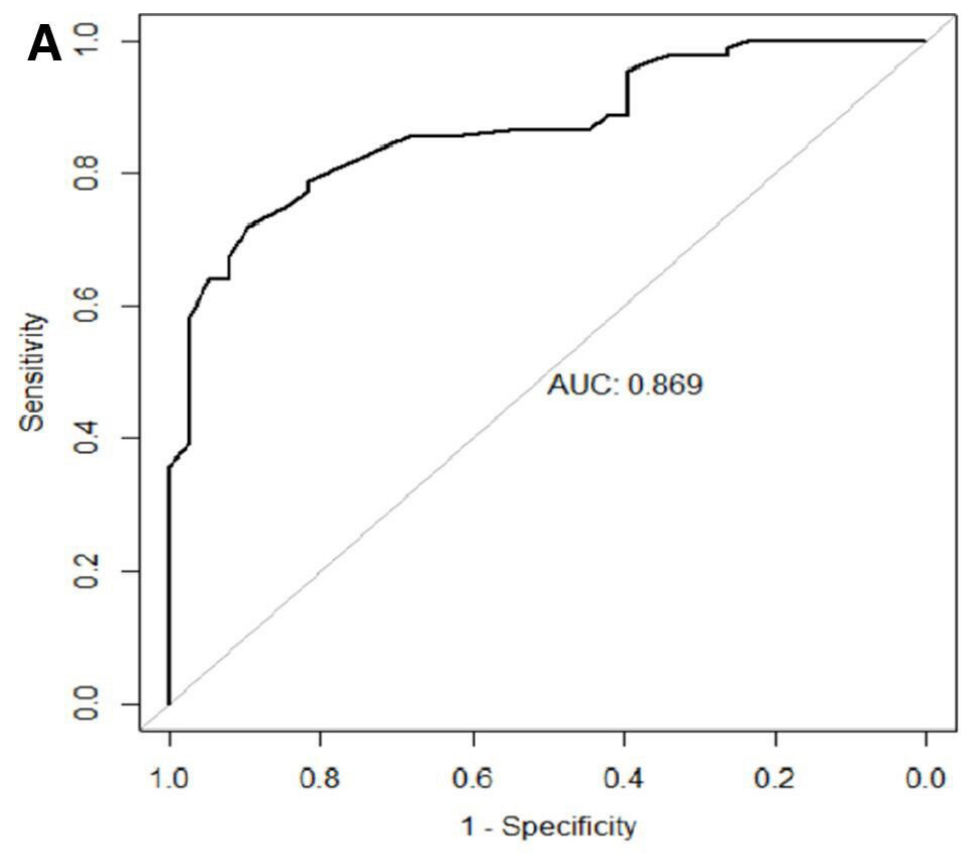

Sensitivity $=71.91 \%$, Specificity $=89.47 \%$

AUC $=0.869$, Cut off value $=0.08$

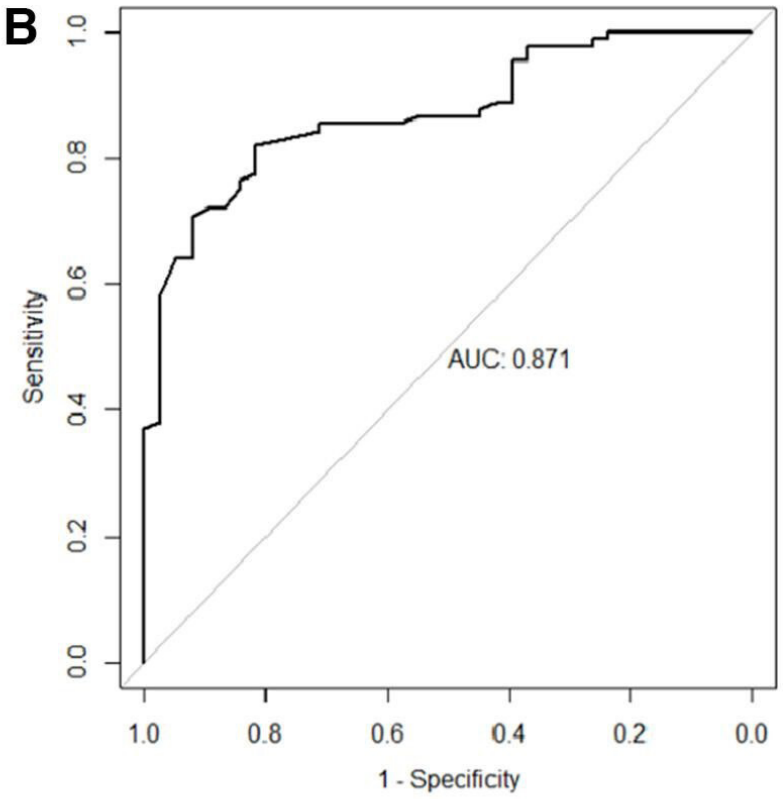

Sensitivity $=82.02 \%$, Specificity $=81.57 \%$

$\mathrm{AUC}=0.871$, Cut off value $=0.49$

Figure 1 (A) Area under curve for ABSI on ROC analysis. (B) Area under curve for the $Z$ _ABSI on ROC analysis. ABSI, A Body Shape Index; ROC, receiver operator characteristics; Z_ABSI, Z score of ABSI.

were calculated. DXA imaging was done for total body fat per cent $(\% \mathrm{TBF})$, truncal fat per cent $(\% \mathrm{TF})$ and truncal fat mass (TFM).

Further, 1.5 T MR imaging (T1-weighted axial scans between L2/L3 vertebrae ${ }^{13}$ were done for volumetric assessment of abdominal adipose tissue compartments, viz., SCAT (anterior, posterior, superficial \& deep), total SCAT, intraperitoneal adipose tissue (IPAT) and retroperitoneal adipose tissue (RPAT) and total IAAT. ${ }^{14}$ In addition, pancreatic volume and liver span (surrogate measures of pancreatic and hepatic fat, respectively) were quantified as mentioned in our previous report. The detailed protocols for MRI and DEXA are available in the same study. ${ }^{13}$ Due to logistic factors, MRI and DXA imaging were performed only in a representative sample size of 85 cases and 38 controls. Further, anthropometric indices namely ABSI, HI and the ARI were calculated using formulae mentioned below: (a) ABSI=WC $(\mathrm{cm}) \times$ weight $(\mathrm{kg})^{-2 / 3} \times$ height $(\mathrm{m})^{5 / 6}=\mathrm{WC} / \mathrm{BMI}^{2 / 3} \times$ height $^{1 / 25}$; (b) HI=hip circumference $(\mathrm{cm})(\mathrm{H} /$ (average height of the group $)^{0.310} \times(\mathrm{W} / \text { average weight for the group })^{0.48215}$.

To control for gender and age-specific differences in $\mathrm{ABSI}$ and HI, Z scores were derived using the formula $\mathrm{Z}$ index $=$ index - index_mean/index_sd, where index denotes ABSI or HI for each individual in the study, index_mean is the mean value for individuals of the same age and sex, and index_sd is the SD. ${ }^{5}$ (c) ARI: It is calculated as the product of the logarthimic odd ratios from separate nonlinear regressions of the four indicators, namely, height, BMI, ABSI and HI. ${ }^{15}$

\section{Statistical analysis}

Data were checked for normality and summarized as Means $\pm \mathrm{SD} /$ median with IQR as appropriate. Spearman's correlation analysis was done. Receiver operator characteristics (ROC) with area under the curve (AUC) analysis was applied to test for sensitivity, specificity and to derive cut-off values for the indices. $P<0.05$ was considered statistically significant. Statistical Package for Social Sciences (SPSS V.21, SPSS, Chicago, Illinois, USA) was used for data analysis.

\section{RESULTS}

Significantly higher mean values were observed in cases for WC, WHR, WHt-R, truncal skinfolds and peripheral skinfolds (table 1). Data on volumes of SCAT, IAAT, pancreas and liver span in cases and controls are shown in online supplementary table 1 .

\section{ABSI}

The median values of ABSI with IQR in cases and controls were 0.082 with IQR $(0.081-0.085)$ and 0.081 with IQR $(0.07-0.08)$, respectively, with no significant differences $(P=0.16)$. In cases, significant positive correlations of the ABSI with age, WHR, WHt-R, mid-arm circumference, subscapular skinfolds and total truncal skinfolds whereas in controls, significant positive correlations were observed only for thigh and abdominal skinfolds and WHt-R. On DXA, significant positive correlation was observed in cases for ABSI with \% TBF, \% TF and TFM, while in controls, no significant correlation was observed 
Table 3 Correlation analysis of ARI in cases and controls

\begin{tabular}{|c|c|c|c|c|}
\hline \multirow{3}{*}{$\begin{array}{l}\text { Anthropometric measures and variables of } \\
\text { body composition }\end{array}$} & \multicolumn{4}{|l|}{ ARI } \\
\hline & \multicolumn{2}{|c|}{ Controls $(n, 38)$} & \multicolumn{2}{|c|}{ Cases $(n, 85)$} \\
\hline & rho & $P$ value & rho & $P$ value \\
\hline Age (years) & -0.11 & 0.51 & 0.04 & 0.71 \\
\hline $\mathrm{BMI}\left(\mathrm{kg} / \mathrm{m}^{2}\right)$ & -0.20 & 0.21 & -0.42 & $<0.01$ \\
\hline WHR & 0.17 & 0.30 & 0.45 & $<0.01$ \\
\hline WHt-R & 0.44 & $<0.01$ & 0.11 & 0.28 \\
\hline Mid arm circumference & -0.16 & 0.33 & -0.24 & $<0.05$ \\
\hline Mid-thigh circumference & -0.03 & 0.83 & -0.40 & $<0.01$ \\
\hline \multicolumn{5}{|l|}{ Skinfolds (mm) } \\
\hline Biceps & 0.23 & 0.18 & 0.13 & 0.24 \\
\hline Triceps & -0.04 & 0.82 & -0.10 & 0.35 \\
\hline Thigh & 0.34 & $<0.05$ & -0.20 & 0.06 \\
\hline Calf & 0.13 & 0.43 & 0.17 & 0.09 \\
\hline Peripheral skinfolds (total) & 0.20 & 0.22 & 0.40 & 0.34 \\
\hline Subscapular & 0.34 & 0.22 & -0.07 & 0.48 \\
\hline Subscapular triceps ratio & 0.25 & 0.14 & 0.12 & 0.25 \\
\hline Suprailiac (horizontal) & -0.02 & 0.99 & -0.13 & 0.21 \\
\hline Suprailiac (vertical) & 0.09 & 0.59 & -0.13 & 0.21 \\
\hline Suprailiac (average) & 0.13 & 0.42 & -0.14 & 0.19 \\
\hline Abdominal (vertical) & 0.15 & 0.40 & -0.30 & $<0.01$ \\
\hline Abdominal (horizontal) & 0.20 & 0.28 & -0.28 & $<0.01$ \\
\hline Abdominal skinfolds (total) & 0.05 & 0.77 & -0.32 & $<0.01$ \\
\hline Truncal skinfolds (total) & 0.13 & 0.43 & -0.24 & $<0.05$ \\
\hline Total body fat (\%) (on DXA) & 0.18 & 0.25 & -0.15 & 0.18 \\
\hline Truncal fat (\%) & 0.09 & 0.55 & -0.16 & 0.16 \\
\hline Truncal fat mass (kg) & -0.01 & 0.92 & -0.20 & 0.07 \\
\hline \multicolumn{5}{|c|}{ Volumes of abdominal fat, pancreas and liver span on MRI (1.5T) } \\
\hline Anterior SCAT $\left(\mathrm{cm}^{3}\right)$ & 0.09 & 0.58 & -0.05 & 0.59 \\
\hline Posterior SCAT $\left(\mathrm{cm}^{3}\right)$ & 0.04 & 0.81 & -0.07 & 0.52 \\
\hline Superficial SCAT $\left(\mathrm{cm}^{3}\right)$ & 0.06 & 0.69 & -0.10 & 0.34 \\
\hline Deep SCAT $\left(\mathrm{cm}^{3}\right)$ & 0.10 & 0.51 & -0.02 & 0.82 \\
\hline Total abdominal SCAT $\left(\mathrm{cm}^{3}\right)$ & 0.07 & 0.64 & -0.09 & 0.40 \\
\hline Retroperitoneal fat $\left(\mathrm{cm}^{3}\right)$ & -0.13 & 0.41 & -0.04 & 0.70 \\
\hline Intraperitoneal fat $\left(\mathrm{cm}^{3}\right)$ & -0.21 & 0.18 & -0.05 & 0.59 \\
\hline Total intra-abdominal fat $\left(\mathrm{cm}^{3}\right)$ & -0.19 & 0.23 & -0.05 & 0.58 \\
\hline Pancreatic volume $\left(\mathrm{cm}^{3}\right)$ & -0.21 & 0.20 & -0.13 & 0.20 \\
\hline Liver span (mm) & 0.40 & 0.07 & 0.08 & 0.40 \\
\hline
\end{tabular}

$P<0.05$ : statistically significant.

Significant $P$ values are shown in bold.

ARI, Anthropometric Risk Index; BMI, body mass index; DXA, dual energy X ray absorptiometry; SCAT, subcutaneous abdominal adipose tissue; WHR, waist-to-hip ratio; WHt-R, waist -to-height ratio.

for ABSI with the same variables. On MRI, significant positive correlations were observed in cases for ABSI with volumes of IPAT, RPAT and total IAAT, whereas moderately significant correlations were observed for volumes of all depots of abdominal SCAT (anterior, posterior, superficial, deep and total). In contrast to this pattern, no significant correlation was observed for volumes of abdominal SCAT and IAAT in controls. Furthermore, no significant correlations were observed for ABSI with liver span and pancreatic volume (table 2). ROC analysis for ABSI showed sensitivity of $71.9 \%$, specificity of $89.4 \%$ with AUC 0.86 for a cut-off value of 0.08 (figure 1A). 
Table 4 Correlation analysis of $Z_{-}$ABSI and $Z_{-} H I$ in cases and controls

\begin{tabular}{|c|c|c|c|c|c|c|c|c|}
\hline \multirow{3}{*}{$\begin{array}{l}\text { Anthropometric measures and variables of } \\
\text { body composition }\end{array}$} & \multicolumn{4}{|l|}{ Z_ABSI } & \multicolumn{4}{|l|}{ Z_HI } \\
\hline & \multicolumn{2}{|c|}{ Controls (n, 38) } & \multicolumn{2}{|c|}{ Cases $(n, 85)$} & \multicolumn{2}{|c|}{ Controls (n, 38) } & \multicolumn{2}{|c|}{ Cases $(n, 85)$} \\
\hline & rho & $P$ value & rho & $P$ value & rho & $P$ value & rho & $P$ value \\
\hline BMI $\left(\mathrm{kg} / \mathrm{m}^{2}\right)$ & -0.31 & 0.07 & -0.09 & 0.39 & -0.36 & 0.03 & -0.17 & 0.54 \\
\hline WHR & 0.12 & 0.50 & 0.71 & $<0.001$ & -0.65 & $<0.001$ & 0.50 & $<0.001$ \\
\hline WHt-R & 0.77 & $<0.001$ & 0.53 & $<0.001$ & 0.42 & 0.01 & 0.09 & 0.42 \\
\hline Mid arm circumference & -0.11 & 0.53 & 0.07 & 0.50 & -0.13 & 0.47 & 0.07 & 0.50 \\
\hline Mid-thigh circumference & 0.319 & 0.07 & -0.16 & 0.12 & 0.15 & 0.39 & 0.06 & 0.57 \\
\hline \multicolumn{9}{|l|}{ Skinfold measurement (mm) } \\
\hline Biceps & -0.15 & 0.38 & -0.008 & 0.94 & -0.07 & 0.71 & -0.09 & 0.38 \\
\hline Triceps & -0.29 & 0.10 & 0.24 & 0.02 & -0.21 & 0.25 & 0.12 & 0.27 \\
\hline Thigh & 0.25 & 0.15 & 0.05 & 0.65 & -0.07 & 0.68 & -0.06 & 0.61 \\
\hline Calf & -0.14 & 0.44 & 0.30 & 0.00 & -0.27 & 0.12 & 0.30 & $<0.01$ \\
\hline Peripheral skinfolds (total) & 0.69 & $<0.001$ & 0.19 & 0.08 & 0.65 & $<0.001$ & -0.05 & 0.65 \\
\hline Subscapular skinfolds (mm) & 0.17 & 0.34 & 0.23 & 0.03 & 0.03 & 0.88 & -0.17 & 0.12 \\
\hline Subscapular-triceps ratio & 0.47 & $<0.01$ & 0.11 & 0.31 & 0.25 & 0.51 & -0.39 & $<0.001$ \\
\hline Suprailiac (horizontal) & -0.06 & 0.75 & 0.19 & 0.08 & 0.01 & 0.96 & 0.03 & 0.77 \\
\hline Suprailiac (vertical) & -0.03 & 0.88 & 0.19 & 0.06 & -0.11 & 0.57 & -0.92 & 0.39 \\
\hline Suprailiac (average) & -0.04 & 0.83 & 0.20 & 0.06 & -0.08 & 0.64 & -0.03 & 0.75 \\
\hline Abdominal (vertical) & 0.22 & 0.25 & 0.12 & 0.28 & 0.15 & 0.42 & 0.07 & 0.52 \\
\hline Abdominal (horizontal) & 0.29 & 0.14 & 0.07 & 0.52 & 0.29 & 0.13 & 0.07 & 0.52 \\
\hline Abdominal skinfolds (total) & 0.35 & 0.05 & 0.07 & 0.50 & 0.21 & 0.29 & -0.03 & 0.81 \\
\hline Truncal skinfolds (total) & 0.24 & 0.16 & 0.18 & 0.08 & 0.42 & $<0.05$ & 0.03 & 0.81 \\
\hline Total body fat (\%) (on DXA) & -0.05 & 0.76 & 0.09 & 0.42 & -0.10 & 0.56 & -0.09 & 0.40 \\
\hline Truncal fat (\%) (on DXA) & -0.11 & 0.52 & 0.14 & 0.23 & -0.17 & 0.31 & -0.13 & 0.25 \\
\hline \multicolumn{9}{|c|}{ Volumes of abdominal fat, pancreas and liver span on MRI (1.5T) } \\
\hline Anterior SCAT $\left(\mathrm{cm}^{3}\right)$ & -0.21 & 0.22 & 0.32 & $<0.01$ & -0.24 & 0.15 & 0.02 & 0.87 \\
\hline Posterior SCAT $\left(\mathrm{cm}^{3}\right)$ & 0.04 & 0.80 & 0.23 & $<0.05$ & -0.02 & 0.91 & -0.09 & 0.43 \\
\hline Superficial SCAT $\left(\mathrm{cm}^{3}\right)$ & -0.13 & 0.45 & 0.26 & $<0.05$ & -0.19 & 0.27 & -0.09 & 0.40 \\
\hline Deep SCAT $\left(\mathrm{cm}^{3}\right)$ & 0.10 & 0.56 & 0.27 & $<0.05$ & 0.02 & 0.89 & -0.02 & 0.89 \\
\hline Total Abdominal SCAT & -0.08 & 0.62 & 0.29 & $<0.01$ & -0.15 & 0.39 & -0.08 & 0.47 \\
\hline Retroperitoneal fat $\left(\mathrm{cm}^{3}\right)$ & -0.12 & 0.49 & 0.24 & $<0.05$ & -0.208 & 0.22 & -0.03 & 0.80 \\
\hline Intraperitoneal fat $\left(\mathrm{cm}^{3}\right)$ & -0.09 & 0.58 & 0.21 & 0.05 & -0.18 & 0.29 & -0.27 & $<0.05$ \\
\hline Total intra-abdominal fat $\left(\mathrm{cm}^{3}\right)$ & -0.11 & 0.54 & 0.25 & $<0.05$ & -0.19 & 0.26 & -0.21 & $<0.05$ \\
\hline Pancreatic volume $\left(\mathrm{cm}^{3}\right)$ & -0.19 & 0.27 & 0.06 & 0.57 & -0.25 & 0.14 & 0.02 & 0.84 \\
\hline Liver span (mm) & 0.20 & 0.23 & 0.07 & 0.50 & 0.08 & 0.65 & -0.26 & $<0.05$ \\
\hline
\end{tabular}

$P<0.05$ : statistically significant.

Significant $P$ values are shown in bold.

ABSI, A Body Shape Index; BMI, body mass index; DXA, dual energy X ray absorptiometry; HI, Hip Index; SCAT, subcutaneous abdominal adipose tissue; WHR, waist-to-hip ratio; WHt-R, waist-to-height ratio; Z_ABSI, Z score of ABSI; Z_HI, Z score of HI.

\section{Z score of A Body Shape Index (Z ABSI)}

The median values of ABSI_Z score in cases, 0.64 with IQR (0.12-1.4) and controls, 1.02 with IQR $(0.24-1.82)$ showed no significant difference $(\mathrm{p}=0.65)$. However, in cases, significant positive correlation was observed for this index with WHR and WHt-R, while the correlation coefficient of former was significantly higher than that of latter. Among skinfold measurements, significant positive correlation was observed for Z_ABSI with triceps, subscapular and calf skinfolds in cases, whereas in controls, significant positive correlation was observed for WHR, total peripheral skinfolds and subscapular-triceps ratio. On MRI, significant correlations were observed in cases for volumes of anterior, posterior, deep and superficial and total SCAT, IPAT, RPAT and total IAAT. Importantly, no significant correlation was observed with pancreatic volume and liver span with Z_ABSI (table 3). ROC analysis showed sensitivity of $82.0 \%$ and specificity 
A

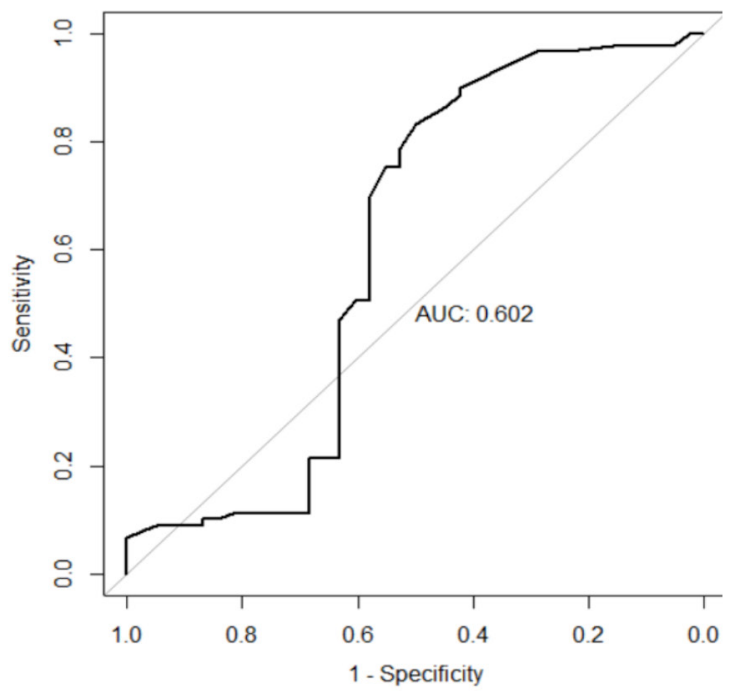

Sensitivity $=83.14 \%, \quad$ Specificity $=50.00 \%$

$\mathrm{AUC}=0.602$, Cut off value $=94.76$
B

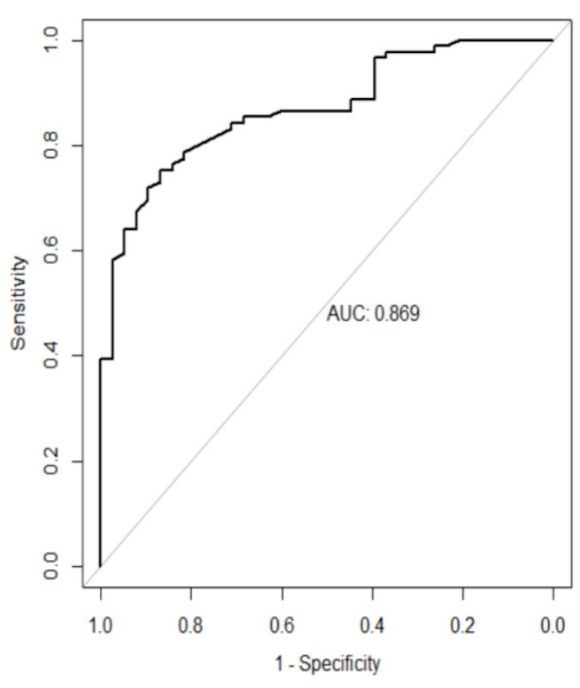

Sensitivity $=75.28 \%$, Specificity $=86.84 \%$

$\mathrm{AUC}=0.869$, Cut off value $=-0.49$

Figure 2 (A) Area under curve for the $\mathrm{HI}$ on ROC analysis (B) Area under curve for $\mathrm{Z}_{-} \mathrm{HI}$ on ROC analysis. HI, Hip Index; ROC, receiver operator characteristics; Z_HI, Z score of the Hip Index.

of $81.5 \%$ with AUC 0.87 for $\mathrm{Z} \_$ABSI cut-off value of 0.49 (figure 1B).

\section{Z HII}

The median value of the $\mathrm{Z}_{-} \mathrm{HI}$ in cases: 0.35 with IQR: $(-0.96$ to 0.31$)$ was significantly lower $(\mathrm{p}=0.01)$ as compared with controls, 0.11 with IQR (-0.63 to 0.87)]. In cases, significant positive correlation was observed for $Z_{-}$HI with WHR and calf skinfolds, but significant negative correlation was observed for subscapular-triceps ratio, volumes of IPAT, IAAT and liver span. Contrastingly, negative correlation with high significance was observed for Z_HI with BMI, whereas significantly positive correlation was observed for WHt-R and sum of total truncal and peripheral skinfolds in controls. On MRI, no significant correlation was observed for $\mathrm{Z}_{-}$HI with liver span, volumes of pancreas, SCAT, IPAT, RPAT and total IAAT in controls (table 4). ROC analysis showed sensitivity of $75.2 \%$ and specificity of $86.8 \%$ with AUC 0.87 for Z_HI cut-off value of -0.49 (figure $2 B$ ).

\section{ARI}

The median values for ARI in cases: 1.02, IQR (0.851.16) and controls: 1.05 , IQR $(0.85-1.25)$ did not differ significantly. Spearman's correlation analysis showed significant negative correlation in cases for ARI with BMI, WHR, mid-arm circumference and mid-thigh circumference. In addition, significant negative correlations were observed for ARI with TFM, abdominal skinfolds (vertical and horizontal) and total truncal skinfolds. In controls, significant positive correlation was observed for ARI with WHt-R and thigh circumference only. No significant correlation was observed for ARI with TFM, lean mass, $\% \mathrm{TBF}$ and volumes of all abdominal adipose tissue depots, pancreas and liver span on MRI (table 3). On ROC analysis, the AUC of 0.58 for ARI showed $83.1 \%$ sensitivity with $50 \%$ specificity for a cut-off value of 1.05 (figure 3).

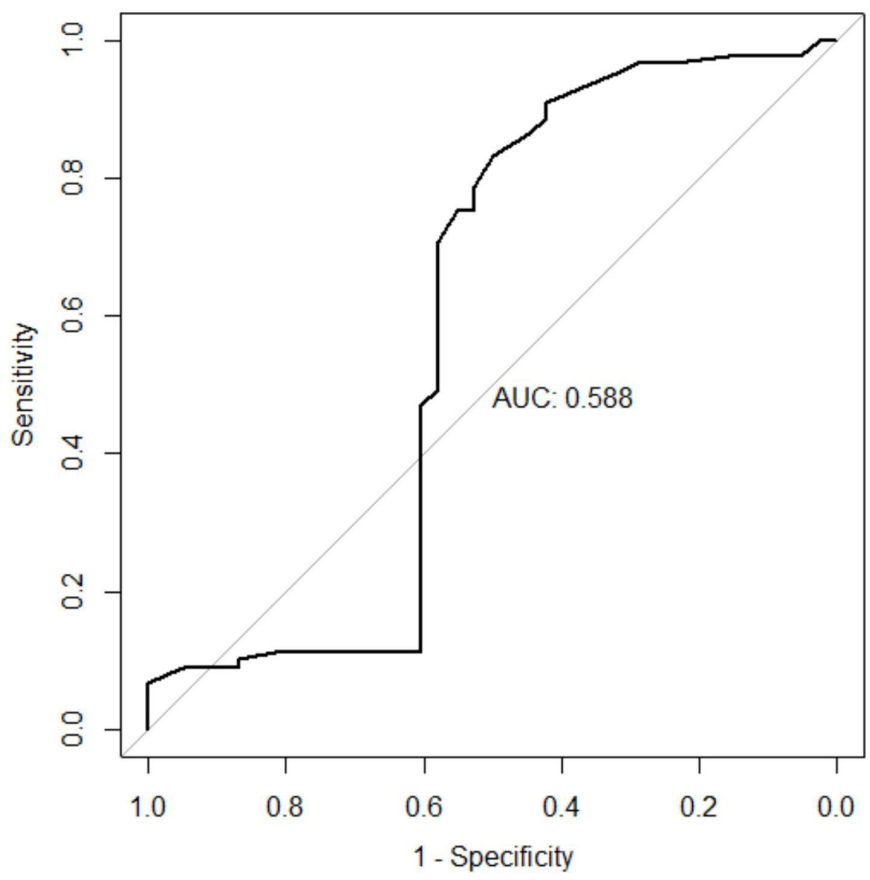

Sensitivity $=83.14 \%$, Specificity $=50.00 \%$

$$
\mathrm{AUC}=0.58, \text { Cut off value }=1.05
$$

Figure 3 AUC for the ARI on ROC analysis. ARI, Adiposity Risk Index; AUC, area under the curve; ROC, receiver operator characteristics. 


\section{DISCUSSION}

Abdominal obesity and T2DM are significant risk factors for cardiovascular events in South Asians, at any given BMI. ${ }^{16}$ In the current study, we report significantly positive correlations of the ABSI and Z_ABSI with SCAT and IAAT volumes, and anthropometric measures in nonobese patients with T2DM. Importantly, we observed superior predictive value of the $Z_{-}$ABSI index for abdominal adiposity in non-obese patients with T2DM as compared with ABSI and other indices, irrespective of age and gender.

The ABSI correlates with mortality risk associated with abdominal obesity while showing minimal confounding effects of weight, height and BMI. ${ }^{6}$ In a large study on non-diabetic, Caucasian subjects aged between 19 and 76 years and residing in Italy, Bertoli $e t a l^{8}$ reported significant association of the ABSI with all determinants of metabolic syndrome and IAAT thickness, latter measured using abdominal ultrasonography. When ABSI was combined with BMI, the association with IAAT thickness improved with better predictive accuracy for hypertriglyceridemia, low high density lipoprotein (HDL) cholesterol and impaired fasting glucose, even after adjustment for confounders. ${ }^{8}$ These authors concluded that ABSI was a useful index for evaluating the independent contribution of $\mathrm{WC}$, in addition to BMI, as a surrogate measure for central obesity and cardiometabolic risk. However, the Z_ABSI was not applied in the study by Bertoli $e t a l^{8}$ despite a large sample size with data of abdominal adipose tissue determined by ultrasonography. In comparison, the correlations of the Z_ABSI and ABSI with MRI-determined SCAT and IAAT volumes in our study on non-obese Asian Indian patients with T2DM are novel observations, despite a smaller but representative sample size. A study on elderly (mean age: $64 \pm 12$ years) Japanese patients with T2DM $(n, 607)$, showed that ABSI and Z_ABSI were significantly associated with intraabdominal fat area (estimated by dual-impedance analyzer and defined as 'visceral fat area'), and arterial stiffness (estimated by brachial-ankle pulse wave velocity). In this study, ABSI was strongly associated with IAAT thickness but not with BMI. ${ }^{17}$

The observations of the current study are also similar to the studies mentioned above; however, patients with T2DM in our study are younger and non-obese, and we carried out more detailed and accurate estimation of multiple adiposity depots, skinfolds and body fat as compared with the former studies. Importantly, our study is based on MRI which is superior to bioimpedance (as used by Khalil et $\mathrm{al}^{18}$ ) and ultrasonography (as used by Gönül et $a l^{19}$ ) for estimation of adiposity depots, as MRI uses magnetic field and radio waves to accurately quantify abdominal adipose tissue volume. ${ }^{20}$ Further, previously no research has been done on correlation statistics of these novel anthropometric indices and liver span and pancreatic volume, especially in Asian Indians.

It is important to note that hip circumference was inversely related to the risk of T2DM in a meta-analysis, but conflicting results were shown in other studies. ${ }^{21}$ Hip circumference is a surrogate measure of gluteal obesity while the hip index (HI) was obtained by transformation of hip circumference using the power law relationship making it unrelated to BMI. A recent study on 687 middleaged, healthy Chinese subjects showed that the HI was a poor predictor of diabetes risk as compared with hip circumference and WHR. ${ }^{22}$ We applied both $\mathrm{HI}$ and $\mathrm{Z}_{-}$ $\mathrm{HI}$ and observed significant negative correlation in cases for HI with volumes of IAAT, RPAT and total IAAT. Interestingly, for Z_HI, significant negative correlations were observed with total IAAT and liver span, but not with RPAT. It is important to note that the HI is an index of gluteal adiposity and the femoral-gluteal adipose is a metabolically static depot due to lower rate of blood flow, lipolysis and fatty acid release as compared with SCAT. In line with the same, in the current study, no significant correlations were noted for HI with all depots of SCAT in cases and controls, as $\mathrm{HI}$ is an index of gluteal obesity. ${ }^{23}$ However, this needs to be investigated further to unravel the functional aspects.

The ARI has been shown to correlate significantly with all determinants of metabolic syndrome as shown in the Third National Health and Nutrition Examination Survey (NHANES III).$^{24}$ In our study, we noted significant correlations of the ARI and Z_ARI with anthropometric measures, thigh, abdominal and truncal skinfolds but not with liver span, volumes of pancreas, SCAT and IAAT. This would have possibly resulted in low specificity of cut-off value, despite high sensitivity of the ARI in this study.

In our previous study, we had shown significant positive correlation of IAAT and liver span with pancreatic volume in non-obese Asian Indians with type 2 diabetes. ${ }^{13}$ Quite strikingly, in the current study, none of the abovementioned anthropometric indices showed significant correlations with pancreatic volume and liver span (surrogate measure of hepatic fat) on MRI, thus undermining the utility of anthropometric indices for detection or prediction of fatty liver or fatty pancreas. This is plausible as pancreatic volume and fatty liver assessment is usually done by ultrasonography or MRI that require precise imaging protocols and in such cases anthropometric indices may not be robust enough to quantify it. ${ }^{25}$ We acknowledge the limitations of the study observations as MRI could not be performed on a large sample size of cases and controls due to reasons of economic feasibility. However, the study observations are worthy to be validated in other populations with larger sample sizes.

In summary, it is important to identify simple and costeffective anthropometric measures that correlate with volumes of abdominal adipose tissue in Asian Indians, because of the close association of abdominal adiposity with cardiovascular risk in Asian Indians. For the first time, we show significant correlation of the $\mathrm{Z}_{-} \mathrm{ABSI}$ index with abdominal adiposity in non-obese Asian Indians with T2DM. The superior predictive accuracy of the Z_ABSI for abdominal adiposity, over ABSI, HI and ARI in this cohort underscores the utility of this index in low-cost clinical settings and epidemiological studies. Clearly, more studies 
are required to validate this index in general population as well as in patients with diabetes.

\section{Author affiliations}

${ }^{1}$ Centre of Nutrition \& Metabolic Research (C-NET), National Diabetes, Obesity and Cholesterol Foundation (N-DOC), Safdarjung Development Area, New Delhi, India ${ }^{2}$ Diabetes Foundation (India), Safdarjung Development Area, New Delhi, India ${ }^{3}$ Centre of Excellence for Diabetes, Metabolic Diseases and Endocrinology, Fortis C-DOC Hospital, New Delhi, India

${ }^{4}$ National Diabetes, Obesity and Cholesterol Foundation, New Delhi, India

${ }^{5}$ Metro Detroit Diabetes and Endocrinology, Southfield, Michigan, USA

${ }^{6}$ Department of Civil Engineering, The City College of New York, New York, New York, USA

Acknowledgements The authors thank the participants of the study. Dr Meetha Mathur and Dr Amrita Ghosh are thanked for their support in this study.

Contributors AM designed the study. SAS performed the study and analyzed the data. JK and NK derived the anthropometric indices from the data. SAS and AM wrote the manuscript and reviewed it critically. All authors approved the manuscript for submission.

Funding The primary study of this cohort was supported by a partial research grant from Merck Ltd, Mumbai, India.

Competing interests None declared.

Patient consent for publication Not required.

Ethics approval The study was approved by the institutional ethics committee (P.NO 4/2009-10/CTAM-EC/FHVK/DO) of Fortis Hospital, New Delhi, India.

Provenance and peer review Not commissioned; externally peer reviewed.

Data availability statement All data relevant to the study are included in the article or uploaded as supplementary information. All data are presented in the tables and in a supplementary file.

Open access This is an open access article distributed in accordance with the Creative Commons Attribution Non Commercial (CC BY-NC 4.0) license, which permits others to distribute, remix, adapt, build upon this work non-commercially, and license their derivative works on different terms, provided the original work is properly cited, appropriate credit is given, any changes made indicated, and the use is non-commercial. See: http://creativecommons.org/licenses/by-nc/4.0/.

ORCID iD

Anoop Misra http://orcid.org/0000-0001-5785-5833

\section{REFERENCES}

1 Hills AP, Arena R, Khunti K, et al. Epidemiology and determinants of type 2 diabetes in South Asia. Lancet Diabetes Endocrinol 2018;6:966-78.

2 Chan JCN, Malik V, Jia W, et al. Diabetes in Asia: epidemiology, risk factors, and pathophysiology. JAMA 2009;301:2129-40.

3 Misra A, Soares MJ, Mohan V, et al. Body fat, metabolic syndrome and hyperglycemia in South Asians. J Diabetes Complications 2018;32:1068-75.
4 Behl S, Misra A. Management of obesity in adult Asian Indians. Indian Heart J 2017;69:539-44.

5 Krakauer NY, Krakauer JC. A new body shape index predicts mortality hazard independently of body mass index. PLOS One 2012;7:e39504.

6 Krakauer NY, Krakauer JC. Untangling waist circumference and hip circumference from body mass index with a body shape index, hip index, and anthropometric risk indicator. Metab Syndr Relat Disord 2018;16:160-5.

7 Bawadi $\mathrm{H}$, Abouwatfa $\mathrm{M}$, Alsaeed S, et al. Body shape index is a stronger predictor of diabetes. Nutrients 2019;11:1018.

8 Bertoli S, Leone A, Krakauer NY, et al. Association of body shape index (ABSI) with cardio-metabolic risk factors: a cross-sectional study of 6081 Caucasian adults. PLoS One 2017;12:e0185013.

9 Lee D-Y, Lee M-Y, Sung K-C. Prediction of mortality with a body shape index in young Asians: comparison with body mass index and waist circumference. Obesity 2018;26:1096-103.

10 Grant JF, Chittleborough CR, Shi Z, et al. The association between a body shape index and mortality: results from an Australian cohort. PLoS One 2017;12:e0181244.

11 Targher G, Day CP, Bonora E. Risk of cardiovascular disease in patients with nonalcoholic fatty liver disease. $N$ Engl J Med 2010;363:1341-50.

12 World Medical Association. World Medical association Declaration of Helsinki: ethical principles for medical research involving human subjects. JAMA 2013;310:2191-4.

13 Misra A, Anoop S, Gulati S, et al. Body fat patterning, hepatic fat and pancreatic volume of non-obese Asian Indians with type 2 diabetes in North India: a case-control study. PLoS One 2015;10:e0140447.

14 Shen W, Wang Z, Punyanita M, et al. Adipose tissue quantification by imaging methods: a proposed classification. Obes Res 2003;11:5-16.

15 Krakauer NY, Krakauer JC. An anthropometric risk index based on combining height, weight, waist, and hip measurements. J Obes 2016;2016:1-9.

16 Misra A, Gopalan H, Jayawardena R, et al. Diabetes in developing countries. J Diabetes 2019;11:522-39.

17 Bouchi R, Asakawa M, Ohara N, et al. Indirect measure of visceral adiposity 'A Body Shape Index' (ABSI) is associated with arterial stiffness in patients with type 2 diabetes. BMJ Open Diabetes Res Care 2016;4:e000188.

18 Khalil SF, Mohktar MS, Ibrahim F. The theory and fundamentals of bioimpedance analysis in clinical status monitoring and diagnosis of diseases. Sensors 2014;14:10895-928.

19 Gönül M, Tatar İdil, Canpolat F, et al. Evaluation of abdominal fat index by ultrasonography and its relationship with psoriasis and metabolic syndrome. Postepy Dermatol Alergol 2017;34:453-6.

20 Franz D, Syväri J, Weidlich D, et al. Magnetic resonance imaging of adipose tissue in metabolic dysfunction. Fortschr Röntgenstr 2018;190:1121-30.

21 Janghorbani M, Momeni F, Dehghani M. Hip circumference, height and risk of type 2 diabetes: systematic review and meta-analysis. Obesity Reviews 2012:13:1172-81.

$22 \mathrm{He} \mathrm{S}$, Zheng Y, Chen X. Assessing a new hip index as a risk predictor for diabetes mellitus. J Diabetes Investig 2018;9:799-805.

23 Frayn K. Adipose tissue as a buffer for daily lipid flux. Diabetologia 2002;45:1201-10.

24 Krakauer NY, Krakauer JC. Anthropometrics, metabolic syndrome, and mortality hazard. J Obes 2018;2018:1-7.

25 Almeida NS, Rocha R, Cotrim HP, et al. Anthropometric indicators of visceral adiposity as predictors of non-alcoholic fatty liver disease: a review. World J Hepatol 2018;10:695-701. 